\title{
Research on the Impacts of Green Finance towards the High-Quality Development of China's Economy-Mechanisms and Empirical Analysis
}

\author{
Gang Yang1* ${ }^{*}$ Yuru Li², Xiaoyi Jiang3 \\ ${ }^{1}$ Business School of Lishui University, Lishui, Zhejiang, China \\ ${ }^{2}$ China (Lishui) Liangshan Research Institute of Lishui University, Lishui, Zhejiang, China \\ ${ }^{3}$ Bohai Bank Beijing Branch, Beijing, China \\ Email: ^158751759@qq.com
}

How to cite this paper: Yang, G., Li, Y. R., \& Jiang, X. Y. (2020). Research on the Impacts of Green Finance towards the HighQuality Development of China's Economy-Mechanisms and Empirical Analysis. Theoretical Economics Letters, 10, 13381357.

https://doi.org/10.4236/tel.2020.106082

Received: October 16, 2020

Accepted: December 22, 2020

Published: December 25, 2020

Copyright $\odot 2020$ by author(s) and Scientific Research Publishing Inc. This work is licensed under the Creative Commons Attribution International License (CC BY 4.0).

http://creativecommons.org/licenses/by/4.0/

(c) (i) Open Access

\begin{abstract}
This paper firstly theoretically analyzes the specific mechanism of Green Finance in promoting the high-quality development of China's economy through three channels: optimizing the industrial structure, improving the ecological environment and supporting the development of the new economy. On this basis, by choosing relevant data of China from 2004 to 2018 to construct the evaluation indicators system of economy quality and synthesizing the high-quality development index of China's economy, then this paper empirically analyzes the impacts of Green Finance on High-Quality Development of China's Economy by using VAR model. It is found that Green Finance has a significant positive correlation with the optimization of China's Economy Quality Index. With the increase of green financial investment, China's industrial structure tends to be rationalized and advanced, and the ecological environment is improved, the new driving force of economic development is constantly strengthened, so as to promote the development of China's economy quality. Finally, according to the research results, the paper puts forward some policy recommendations.
\end{abstract}

\section{Keywords}

Green Finance, High-Quality Development, Function Mechanism, VAR Model

\section{Introduction}

High-Quality Development of Economy was first proposed by the 19th National 
Congress of the Communist Party of China in 2017, indicating that China's economy has shifted from the stage of high-speed growth to the stage of high-quality development. Since the reform and opening-up, China's economic development has made great achievements. The total economic volume has leapt to the second place in the world, and the average annual growth rate of GDP has always maintained above $8 \%$. In 2019, the per capita GDP has exceeded 10,000 US dollars. However, the secondary industry with high pollution and high energy consumption such as coal and steel has been in a dominant position in the industrial layout for many years, and the extensive growth-oriented development mode has led to increasing pressure on resources, ecology and the environment. The problems such as imbalance of supply and demand, the transformation of industrial structure need to be solved urgently. It is necessary to shift from quantitative development to high-quality development, so as to promote the sustainable development of economy and society. The report of the 18 th $\mathrm{Na}$ tional Congress of the Communist Party of China in 2012 pointed out that in the face of the severe situation of tight resource constraints, serious environmental pollution and ecosystem degradation, it is necessary to establish the ecological civilization concept of respecting nature, conforming to nature and protecting nature, putting ecological civilization construction in a prominent position, integrating into all aspects and the whole process of economic construction, political construction, cultural construction and social construction, and advocating green and sustainable development. Financial institutions have responded positively, and green finance policies have gradually become an important force to boost green economic development and promote the optimization and upgrading of industrial structure. By limiting the sources of credit funds for high energy consuming and highly polluting industries, it supports energy conservation, pollution prevention and pollution control, protects the environment, and helps to develop new products, new technologies and new processes of new green energy sources, so that to tap economic potential, promoting the upgrading of China's industrial structure, improving the quality of economic development and promoting the sustainable development of China's economy. Green Finance will play an increasingly important role, especially under the background of international trade frictions and the impacts of COVID-19 pandemic.

High-quality Development of Economy is a new development concept of innovation, coordination, greening, opening and sharing put forward by Chinese government in 2017. The contribution of Green Finance to High-quality Development of Economy is mainly reflected in the three aspects of innovation, coordination and greening. Therefore, we will review the green finance from the following three perspectives: economic growth, industrial structure adjustment and optimization, and green development.

Some scholars believe that the development of green finance has a significant role in promoting economic growth. Markandya et al. (2015) used Dynamic CGE model to empirically study the impacts of green financial development on 
economic growth and emission reduction in developing and developed countries. Their research found that the green climate fund with carbon tax can achieve the dual goals of economic growth and emission reduction. Anderson (2016) believes that green finance is the embodiment of the awareness of resource and environmental protection in the financial industry, which contributes to the green transformation of enterprises and promotes the green development of the overall economy. According to Eric Cowan (1999), green finance is the product of financial industry and environmental protection economy. It is produced to coordinate the common development of the two. Its function is to apply the funds gathered in the financial market to the development of environmental industry. Wang Yao, Pan Dongyang, Zhang Xiao (2016) believes that green finance optimizes the macro development of the economy, improves the micro efficiency of the economy, and complements the traditional economic policies. Feng Wenfang took Inner Mongolia, Tibet, Ningxia, Guangxi, Xinjiang and other ethnic areas as the research objects, discussed various problems encountered in the structural reform of supplying-side in various ethnic areas, and believed that the development of Green Finance is a key factor to realize the rapid economic growth in ethnic areas. Based on the empirical data of 17 cities in Shandong Province from 2006 to 2014, Ji Zhe (2017) constructs a theoretical model to study the influences of green finance on regional economic development, and then establishes a Panel Data model to empirically study the influences, and finds that green finance effectively promotes regional economic growth. Pei Yu, Xu Weifeng, Yang Guoqiao (2018) takes Huzhou, Zhejiang Province as the research object, and empirically analyzes the impacts of green credit on economic growth by establishing a Panel VAR model. Their research results show that Green Finance has a significant positive role in promoting the economic growth of Huzhou. Sun Yanlin and Chen Qingqing (2019) discussed the relationship between green financial development and economic growth by constructing a Panel Vector Autoregressive (PVAR) model based on the provincial data from 2008 to 2017, and found that the development of Green Finance can effectively promote regional economic growth. Taking Zhejiang Province as the research object, Lu Zongkai (2018) empirically studied the relationship between green financial development and regional economic development by building an econometric model. His research results show that the development of Green Finance can improve the efficiency of capital utilization, accelerate the transformation and upgrading of regional industrial structure, and promote the transformation of regional economic development mode.

Some scholars hold the opposite views and think that the impacts of green financial development on economic growth are quite complex and may have adverse effects in some stages. Ning Wei and She Jinhua (2014) believe that the promotion of green finance will have a certain negative impacts on economic growth. Zhang Lei and Li Xinchun (2009) believe that the development of green finance will inhibit economic growth to a certain extent in the short term. Liu 
Sha and Liu Ming (2019) find that there is an interaction among economic growth, environmental quality and green finance. Green finance has a positive effect on environmental quality, but the effect is low. The relationship between green finance and economic growth basically conforms to EKC hypothesis.

Green finance promotes economic growth by promoting the optimization of industrial structure. Based on the inter provincial data of six provinces in Central China from 2004 to 2017, Liu Xia, He Peng (2019) empirically studies the impacts of green financial development on regional economic development by establishing a panel data model. They find that green finance can promote the adjustment of local regional economic structure, and then can promote economic growth. Chen Weiguang, Hu Dang (2011) believe that green finance is conducive to promoting the transformation and upgrading of China's industrial structure through policy guidance, capital orientation. At present, the main reasons for the unsatisfactory effects of the transformation and upgrading of China's industrial structure lie in the information asymmetry and the lack of supervision. Li Yu, Hu Haiya, Lee Ho (2020) analyzed the impacts of green credit on the upgrading of China's industrial structure based on China's provincial panel data. The research results show that green credit has a significant positive role in promoting the overall industrial structure upgrading of the whole country; it has a positive promoting effect on the industrial structure upgrading of the eastern and the central region, while it is not obvious in the western region The reverse force mechanism in the green credit policy will promote the upgrading of the second industrial structure. Based on the time series data of Jiangxi province from 2008 to 2016, Chen Guoqing, Long Y. A. (2018) empirically studies the relationship between green financial development and industrial structure by using the research method of Grey Correlation model. They find that the effect of the loan of banks to Green Industries is not as good as that of restricting loans to Black Industries, that is, and reducing loans to Black Industries has a more positive effect on the optimization and upgrading of Jiangxi's industrial structure.

In terms of promoting green development by green finance, Jeffrey (2019) believes that the development of green finance can not only expand the financing of environmental investment, but also can develop carbon market tools, green central banks, and establish community-based green funds to reduce the coalfriendly energy policies, so as to reduce the environmental investment financing Reduce emissions of carbon dioxide and other harmful gases. Liu Jingyu, Xia Yan, Lin Shimo, Fan Yin (2015) analyze the differential interest rate of high pollution, high emission and high energy consumption industries (Three High Industries) and low pollution, low emission and low energy consumption industries in the perspective of green finance, and apply relevant data of China's Sam table in 2007 and annual capital flow statements, construct a commutable general equilibrium model (CGE model) for empirical analysis. The results show that green financial policies can inhibit the independent investment behavior of enterprises, and can significantly reduce the output of Three High Industries in the 
short and medium term, but it has no significant effect in the long term. Ma Limei, Zhang Xiao (2014) empirically studies the spatial characteristics of haze pollution in China by building a spatial lag model and a spatial error model. The study finds that there is a positive correlation between domestic haze problems and space, and the pollution level is positively correlated with per capita GDP and coal consumption. Green finance can promote the development of clean energy industry, which is conducive to energy conservation and emission reduction. Shao, S. et al. $(2016,2017)$ investigate the driving factors of carbon emission evolution of China's manufacturing industry from 1995 to 2014 with the background of China's carbon emission peaking around 2030. The research results show that the development of green finance is conducive to clean energy investment, thus reducing the total carbon emissions. Zhang Fang, Li Jinxiang, Sun Ce (2020) use panel data model to study the relationship between green financial investment, industrial structure upgrading and high- quality development of economy. The results show that Green financial investment and industrial structure upgrading are the direct driving force of high-quality development; industrial structure upgrading plays a partial intermediary effect in the process of green financial investment promoting highquality development.

Various researches in China and abroad mainly focus on green finance impacts on various aspects of high-quality development of economy, and have summarized some valuable experiences and conclusions. However, in terms of the overall effect of high-quality development, it mainly stays in the basic analysis at the theoretical level, rarely carries out comprehensive and in-depth quantitative analysis; although some scholars have carried out quantitative research, the definition of high-quality development of economy is not completely consistent with the statement of Chinese government, and then there may be a lack of targeted basis for policy-making. Therefore, this paper will explore the construction of high-quality development index according to the definition of Chinese government, so as to provide some theoretical and empirical basis for the future green finance policies.

\section{The Channels and Function Mechanisms of Green Finance Promoting High Quality Development of Economy}

Finance is the blood of economy, and a developed and perfect financial system is an important basis for economic prosperity and stability. Green finance has the important characteristics and functions of finance to promote economy growth, and it also has strong policy nature. By tightening loans scale, raising the interest rate of loans can reduce the output of Three High Industries, and at the same time, it can promoting Green Industries by supporting more loans and lowering down the interests. So green finance can not only reduce the environmental pollution, but also optimize the industrial structure to promote the sustainable development of economy. We can see that Green Finance therefore contributes to 
High-Quality Economic Development mainly through three channels, including optimizing industrial structure, improving ecological environment and supporting the development of the new economy. The specific mechanism of each channel is as following (see Figure 1).

1) Optimize industrial structure and promote economy development coordinately

Industrial structure is one of the most important indexes to evaluate the quality of economic development. The biggest source of environmental pollution is the secondary industry. Through the implementation of green financial policy, the pollution in the secondary industry can be reduced, and the development of high-tech industry and tertiary industry can be promoted, so as to optimize the industrial structure. In order to simplify the description, we call the high input, high consumption and high emission industries as Black Industries, and energy conservation and environmental protection, high-tech industries and new economy industries as Green Industries. Black Industries are mainly concentrated in the secondary industry, while Green Industries are mainly distributed in the secondary and tertiary industries. In response to the government's call to implement green development, commercial banks regulate the capital scale of enterprises in various industries through green financial instruments, reduce the amount of existing loans in Black Industry, restrict the approval and issuance of new loans in Black Industry, limit the total capital scale, increase the loan interest rate, and increase their financial costs. As a result, the scale expansion of these enterprises has been seriously hindered and their internal structure has been optimized, For Green Industries, we should increase the scale of green credit, expand its total capital, reduce its loan interest rate, and reduce its financial costs, so as to promote these industries to expand their production capacity. Through the implementation of differentiated credit policy for black and green

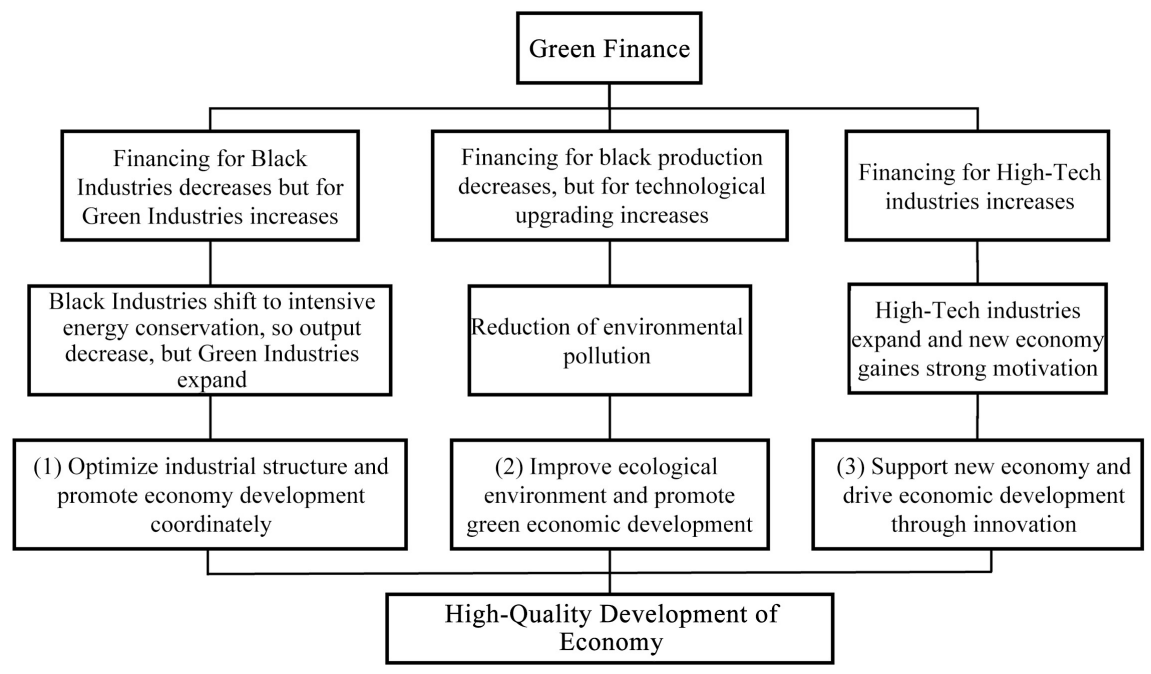

Figure 1. Three channels of green finance promoting high-quality development of economy. 
enterprises in various industries, the cost of Black Industry is increased, the production capacity is reduced, and the cost of Green Industry is reduced, and the output value, growth rate and technical content of the three major industries are continuously adjusted, so as to promote the optimization and upgrading of industrial structure and improve the quality of economic development.

2) Improve ecological environment and promote green economic development

The original intention of implementing green finance is to reduce the pollution caused by human economic activities and relieve the ecological pressure. On the one hand, through the implementation of various green financial policies and tools, commercial banks reduce the loans of black enterprises, restrict black production, and increase the financing of technological transformation and upgrading of enterprises, so that these enterprises can reduce pollution capacity, carry out technical transformation, reduce pollution and meet the requirements of environmental protection; on the other hand, by increasing the financing of energy-saving and environmental protection enterprises, and pollution prevention and control enterprises, it will reduce the energy consumption, reduce pollution emissions and improve the ability of society preventing and controlling pollution, so that to promote the green development of economy.

3) Support new economy and drive economic development through innovation

Increasing financing for the new economy represented by high-tech industries will lay a solid foundation for the long-term sustainable development of China's economy. One of the most important ways to reduce the pressure on the ecological environment is to change the economic development mode from the traditional high-intensity resource input mode to the high-tech intensive economic development mode. Only in this way can we improve the utilization rate of resources, improve the labor productivity, greatly reduce the energy consumption per unit output, so as to promote the sustainable development of economy and society. The new economy involves one or two and three industries, not only refers to the three industries, such as Internet+, Internet of Things, Cloud Computing, e-Commerce, and other emerging industries and business forms, but also includes intelligent manufacturing and large-scale customized production in industrial manufacturing. New Economy Industry can greatly improve labor productivity, reduce resource consumption, reduce carbon emissions and solid waste, and drive economic development by innovation. Therefore, financial support for the new economy should be included in the scope of green finance. Green financial policy promotes the development of new technology, new industry and new mode through various kinds of support for new economy. It can effectively expand the supply and demand scale of high-tech industry, rely on innovation to drive economy, promote green and sustainable economic development, and effectively improve the quality of economic development. 


\section{Empirical Model Construction}

\subsection{Selection, Construction and Description of Variables}

In order to accurately describe the impacts of green finance on economic quality, the response variable is set as Economic Quality Index, the explanatory variable is Green Finance, and the control variable is Financial Deepening Rate. The definitions of each variable are shown in Table 1.

Economy Quality Index (EQI). According to the concepts of High-Quality Development of Economy of innovation, coordination, greening, opening and sharing, which is first put forward in the Fifth Plenary Session of the 18th CPC Central Committee in 2015, this paper divides the measurement system of high-quality level into five aspects: innovation force, coordinated development, green ecology, openness and stability, and sharing and harmony. There are 56 indicators in total, and use 2004 as the base 100 to construct the Economic Quality Index as the explanatory variable.

1) Innovation force. It includes innovation input and innovation output. Innovation input includes $\mathrm{R} \& \mathrm{D}$ investment and personnel input. Innovation output includes per capita patent ownership, technology market turnover and high-tech industry output, with a total of 6 basic indicators.

2) Coordinated development. This paper describes the coordinated development of China's economy from five evaluation items: urban-rural coordination, industrial structure optimization, urbanization level, investment and consumption structure, market mechanism. There are 17 basic indicators in total, such as urban and rural income, industrial structure, urbanization, urban and rural consumption, and Theil index.

3) Green ecology. This paper describes the eco-environmental pressure from four aspects: resource using efficiency, pollution emission, energy conservation and environmental protection, environmental governance, including 11 basic indicators, such as energy consumption per unit GDP, solid waste discharge per unit GDP, waste gas emission per unit GDP, wastewater discharge per unit GDP, and forest coverage rate.

Table 1. Variables definition.

\begin{tabular}{llll}
\hline & Variable & Definition & Symbol \\
\hline $\begin{array}{lll}\text { Explained } \\
\text { variable }\end{array}$ & $\begin{array}{l}\text { Economy Quality } \\
\text { Index }\end{array}$ & $\begin{array}{l}\text { Construct by 56 indicators in total and } \\
\text { use 2004 as the base 100 }\end{array}$ & EQI \\
& Use the item of Energy Saving, & \\
Environmental Protection Projects & and Service Loans, and take logarithm \\
Eariables & Green Finance & $\begin{array}{l}\text { to conduct quantitative analysis on its } \\
\text { marginal effect }\end{array}$ & \\
& & & LNG \\
The control & Financial Deepening & M2/GDP \\
variables & Rate & & FDR \\
\hline
\end{tabular}


4) Openness and stability. The part economic of opening includes the degree of opening up in foreign trade, foreign investment, the proportion of export of labor services, and the amount of foreign investment. The part of stability includes seven basic indicators, such as the level of unemployment rate in towns, Producer Price Index, Consumer Price Index, etc.

5) Sharing and harmony. Sharing and harmony includes four aspects: income distribution, infrastructure construction, basic living security and social pension welfare security. Income distribution is expressed by the proportion of labor income in GDP. Infrastructure includes transportation, medical care, water, electricity and coal supplying facilities, communication facilities. There are 15 indicators in total in this item.

Green Finance (GF). According to the social responsibility reports released by major banks, under the guidance and promotion of government's policies, financial institutions such as banking industry has consciously implemented the requirements of resource and environmental protection and supported green industries, actively shared green development investment opportunities, compressed the development space of polluting enterprises. However, before 2012, there was no unified statistical caliber for green credit data in China's statistical yearbooks, only the item of Energy Saving, Environmental Protection Projects and Service Loans was kept consistent, and it started from 2004. Therefore, in order to truly and accurately reflect the actual situation, this paper chooses to use this item as the proxy variable of Green Finance, takes logarithm to conduct quantitative analysis on its marginal effect, which is expressed by LNGF.

Financial Deepening Rate (FDR). In order to compare with the effect of Green Finance, we examine a number of financial indicators, among which FDR is relatively representative, and the empirical analysis can pass the stability test. Therefore, we use it as a control variable, represented by the ratio of M2/GDP, and actually measure the proportion of exchange conducted by currency as the medium in all economic transactions. Generally speaking, it is a primary indicator to measure a country's economic financialization. The larger the ratio, the higher the degree of economic monetization. However, if the value is too large, the effect of the increase of money supply growth on promoting the increase of real output may gradually decrease.

The data are from China Statistical Yearbook, China Fixed Asset Investment Statistical Yearbook, China Labor Statistical Yearbook, China Energy Statistical Yearbook, China Environmental Statistical Yearbook, China Financial Yearbook, China High Tech Industry Statistical Yearbook, China Population and Employment Statistical Yearbook, China Rural Statistical Yearbook, and National Bureau of Statistics, Chinese Economic Network Database.

\subsection{Basic Test of Variables Sequences}

Each sequence passed ADF unit root test after the first-order difference. The main test results are shown in Table 2. 
Table 2. ADF unit root test results.

\begin{tabular}{ccccc}
\hline Method & Statistic & Prob.* & Cross-sections & Obs \\
\hline \multicolumn{5}{c}{ Null: Unit root (assumes common unit root process) } \\
Levin, Lin \& Chu t & -6.20065 & 0.0000 & 4 & 51 \\
Null: Unit root (assumes individual unit root process) & \\
Im, Pesaran and Shin W-stat & -4.49508 & 0.0000 & 4 & 51 \\
ADF - Fisher Chi-square & 32.9636 & 0.0001 & 4 & 51 \\
PP - Fisher Chi-square & 39.0763 & 0.0000 & 4 & 52 \\
\hline
\end{tabular}

${ }^{*}$ Probabilities for Fisher tests are computed using an asymptotic Chi-square distribution. All other tests assume asymptotic normality.

\subsection{The Establishment of Vector Autoregressive Model (VAR)}

Vector Autoregressive model is often used to predict the interconnected time series system and analyze the dynamic influence of random disturbance on variable system. VAR method constructs the model by taking every endogenous variable as a function of the lag value of all endogenous variables in the system. The mathematical form of VAR (P) model is shown in the following Equation (1):

$$
Y_{t}=A_{1} Y_{t-1}+\cdots+A_{p} Y_{t-p}+B X_{t}+\varepsilon_{t}
$$

Here $Y_{t}$ is a k-dimensional endogenous variable, and $X_{t}$ is a d-dimensional exogenous variable. $A_{1}, \cdots, A_{p}$ and $B$ are the coefficient matrix to be estimated. $\varepsilon_{t}$ is a disturbance vector, which can be correlated with each other in the same period, but not with its own lag value, nor with the variables on the right side of the equation. In this article, EQI, LNGF, FDR are jointly determined by a three-variable VAR model, and the constant is the only exogenous variable. The lag period of the model is determined according to the AIC and SC information criteria. After many tests, we find the AIC and SC information criteria are the smallest when the lag period is 2 . Therefore, the estimated results are as in the following table. For the second order VAR (2) model with endogenous variable lag, see Equation (2) below.

$$
\begin{aligned}
{\left[\begin{array}{c}
\mathrm{EQI}_{t} \\
\mathrm{LNGF}_{t} \\
\mathrm{FDR}_{t}
\end{array}\right]=} & {\left[\begin{array}{c}
-21.94163 \\
2.653163 \\
219.8065
\end{array}\right]+\left[\begin{array}{ccc}
0.685073 & 5.949640 & -0.195435 \\
0.005961 & 0.525435 & -0.014488 \\
0.974384 & -14.07663 & 0.152501
\end{array}\right]\left[\begin{array}{c}
\mathrm{EQI}_{t-1} \\
\mathrm{LNGF}_{t-1} \\
\mathrm{FDR}_{t-1}
\end{array}\right] } \\
& +\left[\begin{array}{ccc}
0.143829 & 3.211937 & 0.098354 \\
-0.003155 & 0.385620 & 0.003381 \\
-0.299640 & 4.525887 & -0.636961
\end{array}\right]\left[\begin{array}{c}
\mathrm{EQI}_{t-2} \\
\mathrm{LNGF}_{t-2} \\
\mathrm{FDR}_{t-2}
\end{array}\right]+\left[\begin{array}{c}
e_{1 t} \\
e_{2 t} \\
e_{3 t}
\end{array}\right]
\end{aligned}
$$

\subsection{The Test of VAR Model}

Since VAR model requires that the variable sequences are stable or have co-integration relationship, so the unit root test is carried out first. It can be seen from the test in Figure 2 that the 6 unit roots are all in the circle, which shows that the VAR system is stable. 
There is a cointegration relationship between the non-agricultural employment rate and every variable at the significance level of $5 \%$, indicating that there is a long-term equilibrium relationship between them; Granger causality test shows that each variable is the Granger cause of non-agricultural employment when it lags behind the second order; the result of VAR model shows that the adjusted $\mathrm{R}^{2}$ is 0.9240 , which means that the total fitting degree of the model is very good. The standard deviation SE is almost zero, and there is no problem of self-correlation by DW test, and the F statistics are large enough, so we can judge that the VAR model is stable and can pass the tests, and the main test results are shown in Table 3 and Table 4.

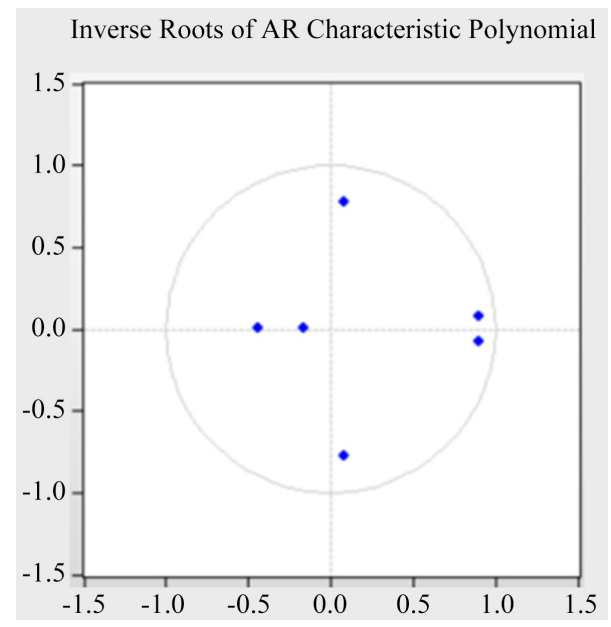

Figure 2. Stability test results of VAR system.

Table 3. Sequences Co-integration test results.

\begin{tabular}{ccccc}
\hline Hypothesized No. of CE $(\mathrm{s})$ & Eigenvalue & Trace Statistic & 0.05 Critical Value & Prob. $^{* *}$ \\
\hline None $^{*}$ & 0.809734 & 34.125 & 29.79707 & 0.0149 \\
At most 1 & 0.513246 & 10.89436 & 15.49471 & 0.2181 \\
At most 2 & 0.056512 & 0.814398 & 3.841466 & 0.3668 \\
\hline
\end{tabular}

Trace test indicates 1 cointegrating eqn(s) at the 0.05 level; ${ }^{*}$ denotes rejection of the hypothesis at the 0.05 level; ${ }^{* *}$ MacKinnon-Haug-Michelis (1999) $p$-values.

Table 4. GRANGER Causality test results.

\begin{tabular}{cccc}
\hline \multicolumn{4}{c}{ Pairwise Granger Causality Tests } \\
\hline \multicolumn{4}{c}{ Sample: 2004 2018 } \\
\hline Lags: 1 \\
\hline Null Hypothesis: & Obs & F-Statistic & Prob. \\
LNGF does not Granger Cause EQI & 14 & 7.9431 & 0.0167 \\
EQI does not Granger Cause LNGF & 14 & 0.06887 & 0.7978 \\
FDR does not Granger Cause EQI & 14 & 4.65917 & 0.0538 \\
EQI does not Granger Cause FDR & 14 & 11.4722 & 0.0061 \\
\hline
\end{tabular}




\section{Analysis of Empirical Results}

In this article, we use Analytic method to calculate the standard error of impulse response, and use the inverse of Cholesky factor of residual covariance matrix to orthogonalize the impulse. Figure 3, Figure 4 show the impulse responses of EQI to the changes of LNGF and FDR. Figure 5, Figure 6 are the results of variance decomposition, which show the contribution rates of LNGF and FDR to urbanization. The term of impact is set as 10 periods because the effects of GF need time to fully display, and 10 periods are long enough and comparatively reasonable.

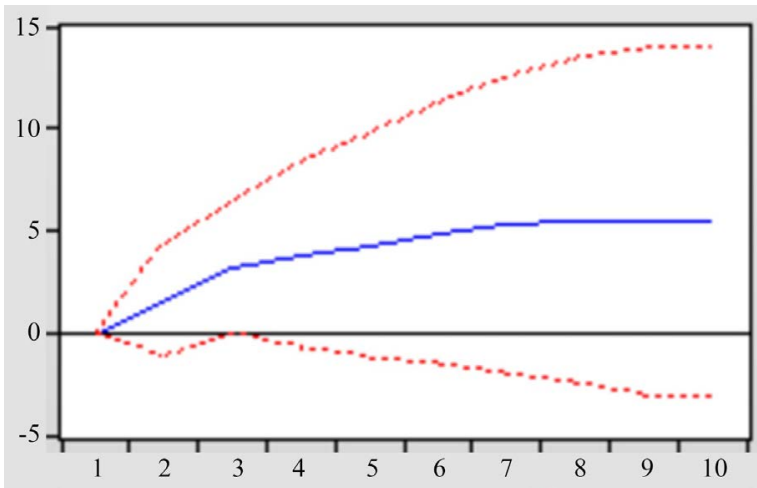

Figure 3. Dynamic impacts of GF on EQI.

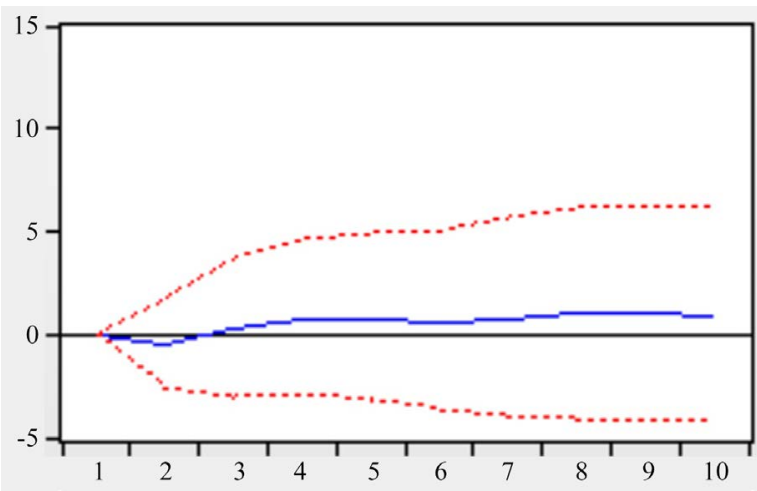

Figure 4. Dynamic impacts of FDR on EQI.

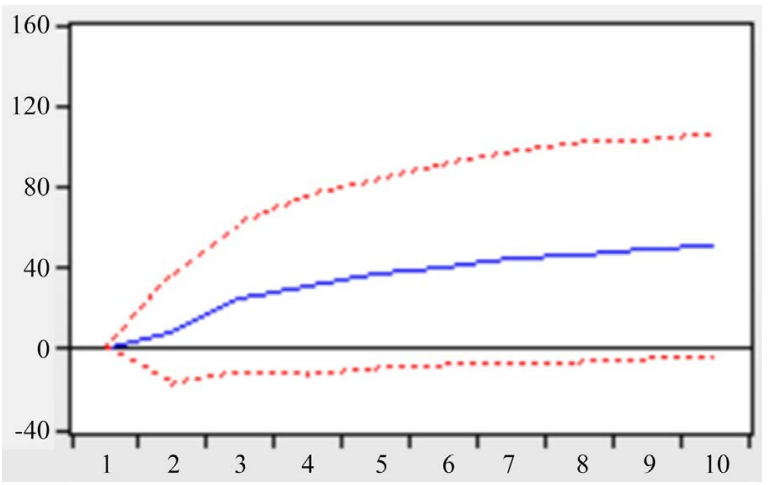

Figure 5. Contribution rate of GF to EQI. 


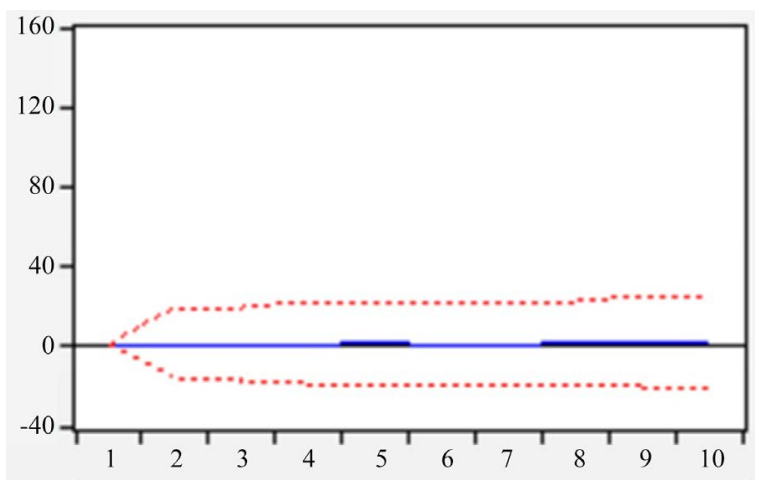

Figure 6. Contribution rate of FDR to EQI.

\subsection{Impulse Response Function}

It can be seen from Figure 3 that after giving GF a positive impact in the current period, EQI will show a long-term stable growth trend. This effect begins to appear in the first period, and continues to increase until the eighth period reaches the maximum value of 5.4406, indicating that GF has great and far-reaching impacts on EQI, which is consistent with the above theoretical analysis. With the gradual promotion of China's green development strategy, financial institutions continue to increase the support of green finance, the proportion of green credit increases, and the proportion of black loans decreases, from the theoretical and empirical analysis results, we can see that the impacts on the upgrading of industrial structure and green economic development are very obvious, which effectively promote the high-quality development of China's economy. Under the circumstances that climate changes have more and more significant impacts on China's as well as the global economy, and international trade frictions are increasingly extending to China's high-end technology bottleneck, we should continue to emphasize and encourage green finance to support economic structure transformation and sustainable development.

It can be seen from Figure 4 that after a positive impact on FDR in the current period, EQI will immediately adjust, and then form a slow but sustained growing trend. This growth begins to appear after the bottom of the second period, and continues to increase until it reaches the maximum value of 1.0050 in the eighth period. Although the marginal influence is relatively small comparing with that of GF, due to the huge base of M2 and GDP in China, the actual absolute impacts of FDR on EQI are larger and lasting. However, at present, China's FDR has exceeded 200\%, far exceeding the average level of the general developing and developed countries, which can be said to have faced a great growth bottleneck. FDR has experienced a slight decline for three consecutive years since 2005, which can explain the initial fluctuation of its impact on EQI to a certain extent; during the subprime mortgage crisis, the Chinese government began to increase the currency issuance significantly in order to maintain stable economic growth, and FDR increased rapidly. As financial institutions have begun to emphasize the impacts of credit instruments on the quality of economic develop- 
ment, so they have consciously adjusted and optimized the structure of financial support, and gradually turned to use green finance to support strategic emerging industries. Therefore, the influence of FDR on EQI is gradually increasing. However, compared with GF which directly affects EQI, the marginal influence is not big enough.

\subsection{Variance Decomposition}

The results of variance decomposition are shown in Figure 5, Figure 6. Comparing Figure 5, Figure 6, we can see that the contribution rate of GF to EQI is far greater than that of FDR.

As can be seen from Figure 5, the contribution rate of GF is rising continuously. It accelerates before the third period, and then slows down from the fourth period, but still maintained a strong upward trend, reaching the highest point of 50.5118 in the 10th period. The impact of GF is relatively more direct and sufficient. It can not only affect the loan amount and interest rate level of energy-saving and environmental protection enterprises, but also indirectly affect the public's cognition to gradually improve the quality of economic development through demonstration effect. Therefore, its direct and indirect effects are very significant. The contribution rate of Financial Deepening indicators is continuously rising, but its value always remains underneath 1.5 , so the growth is very weak, and its marginal contribution rate is very small. FDR reflects the currency issuance ratio, which is mainly reflected in the impacts on all aspects, levels and links of the whole society, including both positive and negative impacts on Green Industry and Black Industry. It does not have the ability to accurately implement targeted support, so the marginal contribution to the improvement of economy quality is not obvious.

\subsection{Robustness Test}

Using Financial Correlation Rate (FCR) to replace FDR for robustness test, and the results show that the model is also stable. In the empirical test results of impulse response and variance decomposition, the sign and value of the impacts of GF on EQI have no significant change. At the same time, we can see that the impacts of FCR on EQI development are also significantly positive. The specific results are shown in Figures 7-10.

\section{Conclusion and Suggestion}

Research conclusions: theoretical analysis shows that green finance promotes high-quality development of economy mainly through three channels, including optimizing industrial structure, improving ecological environment and supporting new economic development, and each channel has its own specific mechanism. The empirical results show that with the continuous promotion of China's green development strategy, financial institutions continue to increase 
the support of green finance, and the amount of green credit is increasing, which has very obvious impacts on the upgrading of industrial structure and green economic development, and effectively promotes the high-quality development of China's economy.

Generally speaking, the development of green finance can better promote the high-quality development of China's economy.

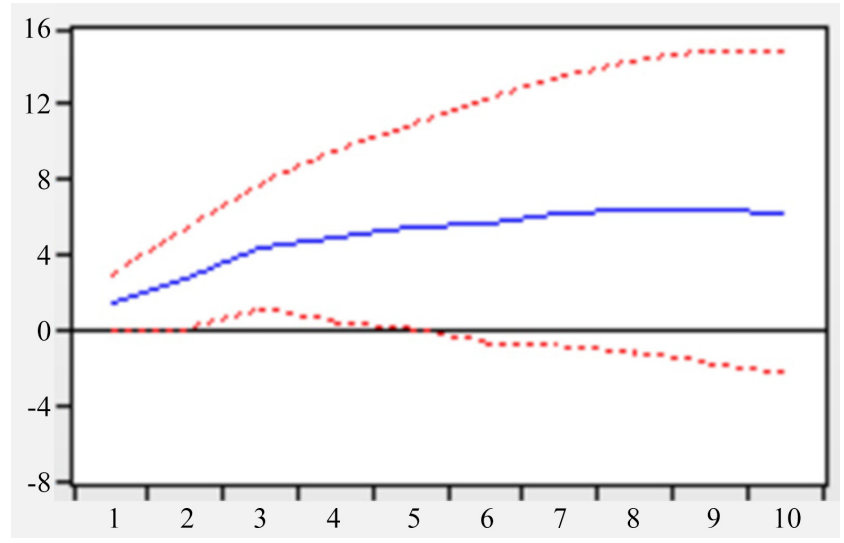

Figure 7. Dynamic impacts of GF on EQI.

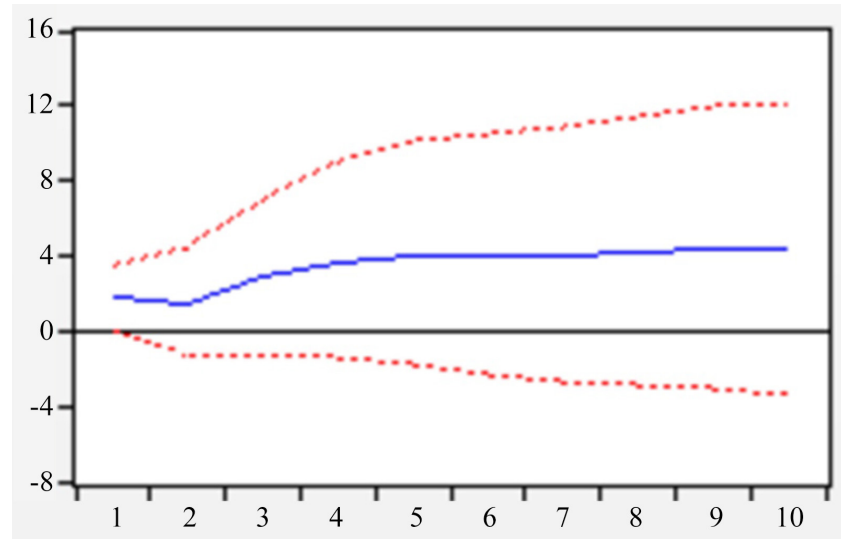

Figure 8. Dynamic impacts of FCR on EQI.

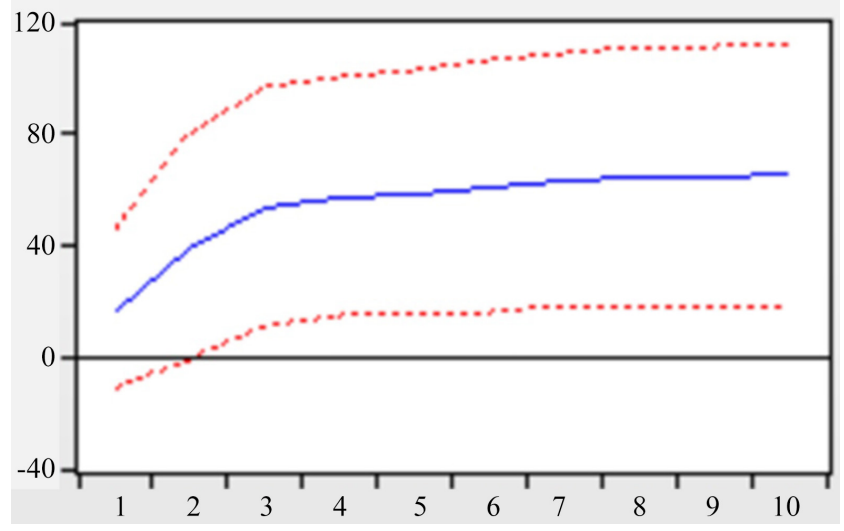

Figure 9. Contribution rate of GF to EQI. 


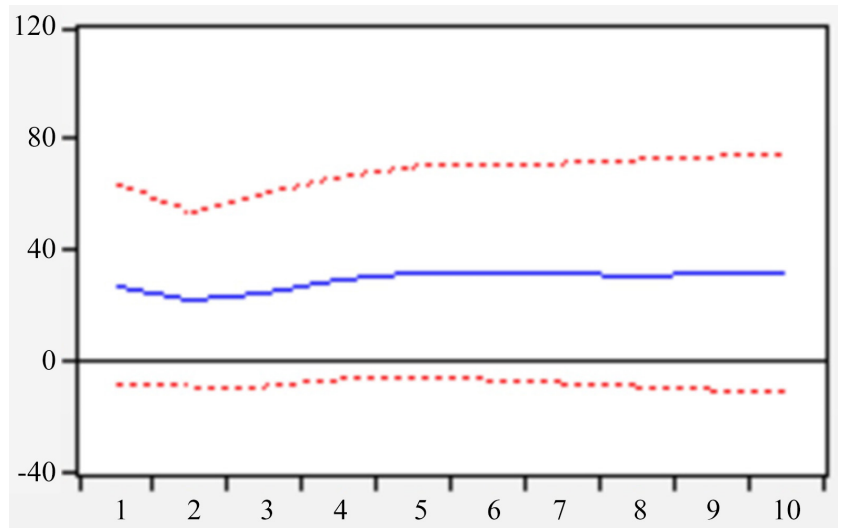

Figure 10. Contribution rate of FCR to EQI.

Under the circumstances that climate changes have more and more significant impacts on China's as well as the global economy, and international trade frictions are increasingly extending to China's high-end technology bottleneck, we should continue to emphasize and encourage green finance to support economic structure transformation and sustainable development, but China's green finance policies are not perfect, and the scale of green finance is far from meeting the demands of market. In order to give full play to the important role of green finance and further use it to boost the high-quality development of China's economy, we believe that we should take measures in the following aspects:

First, we should enhance people's awareness of green development and boost high-quality economic development.

In order to promote high-quality economic development, we must first solve the problem of ideology. Only when all social and economic subjects participate in the whole process, from the end of environmental pollution to the practice of ecological civilization construction concept, can we effectively promote the high-quality economic development by improving the awareness of green development from multiple subjects, multi angles and all-round aspects.

1) We should advocate the public awareness of green consumption. Cultivating green consumption consciousness and advocating green consumption can change consumer preference, solve environmental crisis from the demand side, drive the development of Green Industry through market supply and demand mechanism, and promote the transformation of economic structure from the root. On the one hand, through the correct public opinion guidance, help the public to form the environmental protection concept of caring about environmental problems, supporting energy conservation and emission reduction. On the other hand, encourage and promote personal green consumption, and support the promotion and application of low-carbon environmental protection products and technologies.

2) Enhance the green production awareness of enterprises. Enterprises should establish the concept of green investment, improve the awareness of green development, carry out green investment projects, strengthen technological trans- 
formation and upgrading, and reduce pollution emissions. The government can set up green special fund, innovate green financial market, help small and medium-sized enterprises to solve the problems of financing difficulty and high financing cost through green financial tools, and help small and medium-sized enterprises to carry out low-carbon environmental protection green projects. Large commercial banks should give full play to the advantages of abundant resources to support and guide the green development of enterprises by expanding green credit. Only when all the market participants enhance the awareness of green development and form a joint force, can we promote the green and sustainable development of economy and improve the quality index of economic development.

Secondly, we should increase the scale of green finance so that to promote the optimization and upgrading of China's industrial structure.

In order to play a positive role in promoting green development, resolving excess production capacity and building ecological civilization, China should increase the supply of green credit on the premise of controlling financial risk, and keep the growth rate of green credit higher than the average level of all bank loans. It is necessary to promote the business philosophy, development path, resource allocation and transformation focus of commercial banks to further incline to green finance. In terms of institution establishment, green credit departments or even green sub-branches should be set up to provide credit support for pollution prevention and control, resource conservation and recycling, clean transportation, clean energy, ecological protection. In terms of institution and management process, the commercial banks should give full support to green finance in development planning, organizational structure, risk control, assessment management and resource allocation, and give priority to the important national energy conservation and emission reduction projects, key pollution source control projects, technologies listed in China's key energy conservation promotion catalogue, and companies of energy-saving and emission reduction with innovative technology and good market demand.

Thirdly, we should use green financial policies to develop New Infrastructure and boost rationalization of industrial structure.

In recent years, the Middle Committee of the CPC and the State Council of China has attached great importance to the construction of New Infrastructure. The New Infrastructure includes 5G base station, UHV, intercity high-speed railway and urban rail transit, electric vehicle charging pile and big data center, which highlights the new direction of industrial transformation and upgrading, and conforms to the era characteristics of green economic development. Compared with the traditional infrastructure, all these five fields reflect the general trend of accelerating the development of high-tech industry. New Infrastructure is not only infrastructure construction, but also emerging industries and new economy, because it can closely connect the market and attract large amount of investment. It can not only stimulate the investment demand of upstream and 
downstream, boost consumption, lay a solid foundation for China's economy to tide over short-term difficulties and support long-term prosperity, it can also carry out moderately advanced new infrastructure construction through market mechanism constraints and incentives, form appropriate supply and production capacity, drive the new economy with more than 10 trillion output value, and lay a solid foundation for seizing the commanding heights of the new generation of global information technology. Through targeted green financial incentives, China can promote the practical application of new green technologies and products, and promote the development of green intelligence in new infrastructure construction from the aspects of facility construction and equipment selection, so that to promote the rationalization of industrial structure.

Fourthly, governments should introduce more encouraging and supporting policies to fully mobilize the enthusiasm of banks to carry out green finance.

At present, China's environmental protection industries related supporting policies and incentive mechanisms need to be further improved; some environmental protection enterprises have limited capital strength, single financing channels, and insufficient collateral, which increase the risk of green credit; many environmental protection projects have high management costs, long project duration and are in a state of loss. These problems make the environmental protection industry show the signs of high investment, high risk but low output, and at the same time, it also reduces the motivation of banks to continue to carry out green credit. Therefore, while calling on banks to carry out green credit, the government and other relevant parties should also bear corresponding responsibilities. Government should introduce more encouragement and support policies for green credit related businesses, fully mobilize the enthusiasm of the banking industry, and establish a long-term mechanism for the development of green credit business. It can increase investment in government funds, incorporating green credit into policy-oriented loan, giving loan discount, direct subsidy for green credit, etc., so as to reduce the cost of green credit of banks and improve the return rate of green credit; due to the large capital requirement, the long construction period and high risk of some environmental protection projects, it is difficult for banks to use green credit alone to meet the demand of enterprises, so the government should help to broaden financial channels when necessary, so that to reduce the financing risk of green credit of banks. By these means, we can fully mobilize the enthusiasm of the banking industry to carry out green credit, boost the continuous adjustment and optimization of China's industrial structure, and promote the sustainable green development of economy.

\section{Acknowledgements}

The authors are grateful for financial support from the National Social Science Fund Project (18BJL085), and Zhejiang philosophy and Social Sciences Planning 
Project (19NDJC088YB, 19NDFC382YB).

\section{Conflicts of Interest}

The authors declare no conflicts of interest regarding the publication of this paper.

\section{References}

Anderson, J. (2016). Environmental Finance. In V. Ramiah, \& G. Gregoriou (Eds.), Handbook of Environmental and Sustainable Finance (pp. 307-333). London: Elsevier. https://doi.org/10.1016/B978-0-12-803615-0.00015-7

Chen, G. Q., \& Long, Y. A. (2018). Research on Green Finance Development and Upgrade of Industrial Structure-Empirical Analysis Based on Jiangxi Province. Journal of Contemporary Financial Research, No. 1, 120-128.

Chen, W.-G., \& Hu, D. (2011). An Analysis of the Functional Mechanism and Effect of Green Credit on Industrial Upgrading. Journal of Jiangxi University of Finance and Economics, No. 4, 12-20.

Cowan, E. (1999). Topical Issues in Environmental Finance. Economy and Environment Program for Southeast Asia (EEPSEA), EEPSEA Special and Technical Paper.

Jeffrey (2019). Why Is Green Finance Important? ADBI Working Paper Series, No. 917.

Ji, Z. (2017). Green Financial Impact on Regional Ecological Economy and Countermeasure Research-Taking Shandong Province as an Example. Liaocheng: Liaocheng University.

Li, Y., Hu, H. Y., \& Lee, H. (2020). Empirical Analysis of the Impact of Green Credit on the Upgrading of China's Industrial Structure: Based on Chinese Provincial Panel Data. Economic Research Journal, No. 1, 37-43.

Liu, J. Y., Xia, Y., Lin, S. M., \& Fan, Y. (2015). The Short, Medium and Long Term Effects of Green Credit Policy in China Based on a Financial CGE Model. Chinese Journal of Management Science, No. 4, 46-52.

Liu, S., \& Liu, M. (2019). Green Finance Economic Growth and Environmental Is It Possible for the Environmental Index in the Northwest to Fulfill Change: The Paris Agreement? Modern Economic Science, No. 6, 85-97.

Liu, X., \& He, P. (2019). Research on the Impact of Green Finance on Economic Development in Central China. Journal of Industrial Technological Economics, 38, 78-86.

Lu, Z. C. (2018). Research on Green Finance Development under the Background of Supply Side Structural Reform. Hangzhou: Zhejiang University.

Ma, L. M., \& Zhang, X. (2014). Spatial Effects of Regional Air Pollution and the Impact of Industrial Structure. China Population, Resources and Environment, No. 24, 157-164.

Markandya, A. et al. (2015). Analyzing Trade-Offs in International Climate Policy Options: The Case of the Green Climate Fund. World Development, 74, 93-107. https://doi.org/10.1016/j.worlddev.2015.04.013

Ning, W., \& She, J. H. (2014). Green Finance and Macroeconomic Growth Empirical Research on Relationship. Seeker, No. 8, 62-66.

Pei, Y., Xu, W. F., \& Yang, G. Q. (2018). Green Credit Investment, Green Industry Development and Regional Economic Growth: A Case Study of Huzhou City, Zhejiang Province. Zhejiang Social Sciences, No. 3, 45-54.

Shao, S., Li, X., \& Cao, J. H. (2016). China's Economic Policy Choices for Governing 
Smog Pollution Based on Spatial Spillover Effects. Economic Research Journal, No. 4, 41-50.

Shao, S., Zhang, X., \& Xing, R. (2017). Empirical Decomposition and Peaking Pathway of Carbon Dioxide Emissions of China's Manufacturing SectorGeneralized Divisia Index Method and Dynamic Scenario Analysis. China Industrial Economics, No. 3, 44-63.

Sun, Y. L., \& Chen, Q. Q. (2019). The Impact of Green Finance on Technological Progress and Economic Growth-An Empirical Study Based on PVAR Model. Journal of Finance and Economics, No. 5, 28-33.

Wang, Y., Pan, D. Y., \& Zhang, X. (2016). Research on Green Finance's Contribution to China's Economic Development. Comparative Economic and Social Systems, No. 6, 33-42.

Zhang, F., Li, J. X., \& Sun, C. (2020) Green Finance Delivery and High-Quality Economic Development Research on the Mediating Effect and Moderating Effect Based on the Upgrading of Industrial Structure. Zhejiang Finance, No. 1, 59-69.

Zhang, L., \& Li, X. C. (2009). Empirical Analysis on Contribution Rate of Environmental Protection Investment to Economic Growth in China. Special Zone Economy, No. 3, 267-268. 